\title{
Florid xanthelasmata (yellow lids) in orbital Wegener's granulomatosis
}

Andrew B Tullo, Paul Durrington, Elizabeth Graham, Lennox P Holt, David L Easty, Richard Bonshek, Joan L Noble

\section{Patients}

CASE 1

A 57-year-old man presented in 1973 to the Bristol Eye Hospital with bilateral asymmetrical PUK. He also complained of a blood stained nasal discharge. An $x$ ray of the right maxillary antrum showed mucosal thickening. A chest $x$ ray revealed a well defined rounded opacity in the right upper lobe which was biopsied and found to be 'granulomatous'. A second opacity was present in the right lower lobe. The right hilum was enlarged and a small left pleural effusion was present. In 1978 he developed proptosis of the right eye associated with a palpable mass above the globe and ophthalmoplegia. One year later masses were palpable above and below the globe being continuous on the nasal side and overlaid by a waxy yellow discoloration. (Fig 1). Biopsies of the orbit and sinus revealed granulomatous tissue, but no evidence of vasculitis.

$\mathrm{He}$ was treated with systemic steroids and cyclophosphamide with good effect. When last seen in 1992 his vision was 6/9 in each eye and the inflammatory process was controlled with a maintenance dose of prednisolone $2 \mathrm{mg}$ daily. Over the 14 year period of treatment since their appearance the yellow lid lesions have gradually faded are now only visible on close examination.

In August 1989 anti-neutrophil cytoplasmic antibodies (ANCA) were detected at a titre of $1: 80$. ANCA were negative when retested in October 1990 at which time C-reactive protein was present at $0.033 \mathrm{~g} / \mathrm{l}$. Recent fasting serum triglyceride concentration was $1.38 \mathrm{mmol} / \mathrm{h}$, serum cholesterol $6.47 \mathrm{mmol} / \mathrm{l}$, low density lipoprotein cholesterol (LDL) $4.20 \mathrm{mmol} / \mathrm{l}$, and high density lipoprotein cholesterol (HDL) 1.69 $\mathrm{mmol} / 1$. Apoliprotein $\mathrm{E}$ phenotype was $3 / 3$.

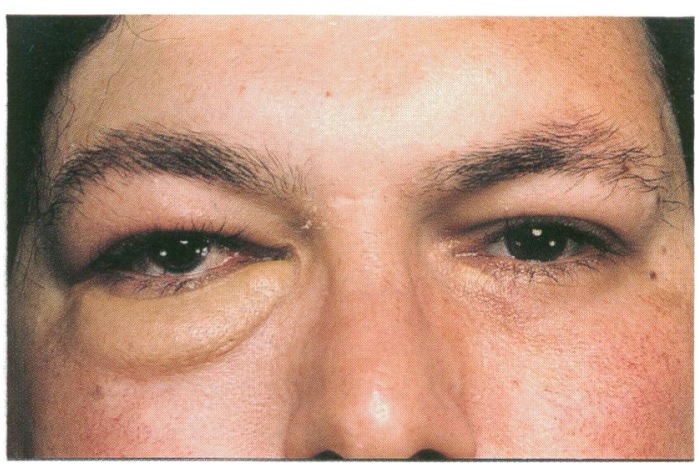

Figure 2 Raised yellow banana-shaped lesion of right lower lid and much smaller lesion on nasal aspect of left

lower lid in case 21987.
Figure 1 Large waxy yellow lesion of the right upper and lower lid in case 1 in 1978.
Wegener's granulomatosis (WG) involves Ophthalmological features include proptosis (Pukema, peripheral ulcerative kerati neuropathy, all of which may be presenting signs of the condition. We describe in the recognition of WG in two othe patients.

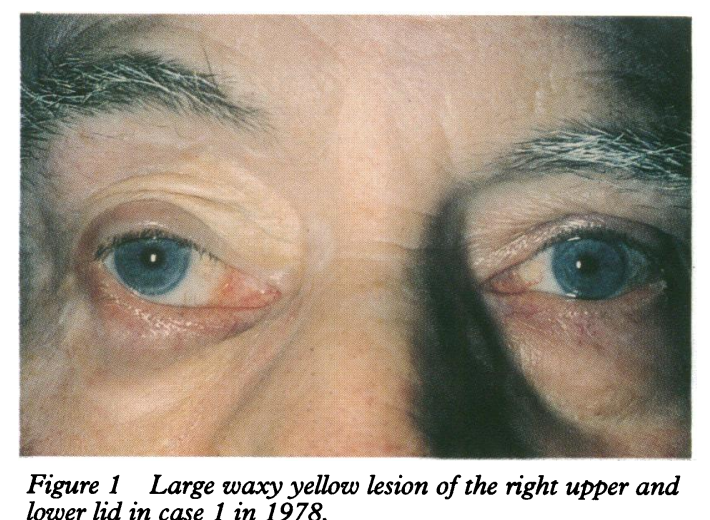




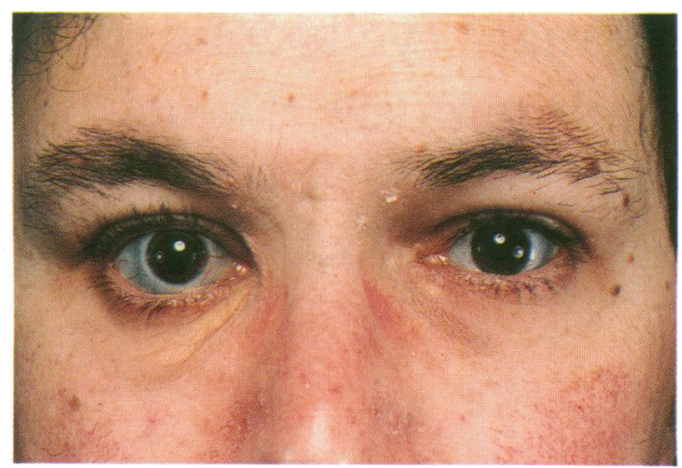

Figure 3 Barely visible lid lesion in case 2 in 1992 after systemic treatment for Wegener's granulomatosis.

\section{CASE 2}

A 29-year-old man presented in 1985 with redness of both eyes due to bilateral sclerokeratitis associated with extensive peripheral corneal melting. One year previously he had been investigated for macroscopic haematuria and polyarthritis. He was treated successfully with topical steroids, but 18 months later developed swelling on both right and left lower eyelids associated with some proptosis and diplopia. Investigations revealed an erythrocyte sedimentation rate of $90 \mathrm{~mm} / \mathrm{h}$, hypergammaglobulinaemia, positive rheumatoid factor, positive antinuclear, gastric parietal and antimitochondrial antibodies. A biopsy of orbital tissue showed an acute vasculitis with polymorphs infiltrating the vessel wall and a chronic inflammatory cell infiltrate around the vessel consistent with a diagnosis of WG. Treatment with systemic steroids was commenced with a good response initially, but in June 1987 he developed gaze evoked amaurosis in the right eye on dextroversion. At this point he was transferred to St Thomas's Hospital, London.

There was proptosis $(4 \mathrm{~mm})$ of the right eye with an extensive xanthelasma in the right lower lid (Fig 2). Movements of the right eye were limited in all directions, but were normal in the left eye. Visual acuity could be corrected to $6 / 9$ in each eye with intact colour vision. Visual fields were full, but for an enlarged right blind spot. Slit-lamp examination revealed bilateral sclerokeratitis with extensive PUK. The right optic disc was markedly swollen with choroidal folds stretching between the optic disc and the macula. A computed tomography scan showed a diffuse opacification of the right orbit consistent with a diagnosis of WG.

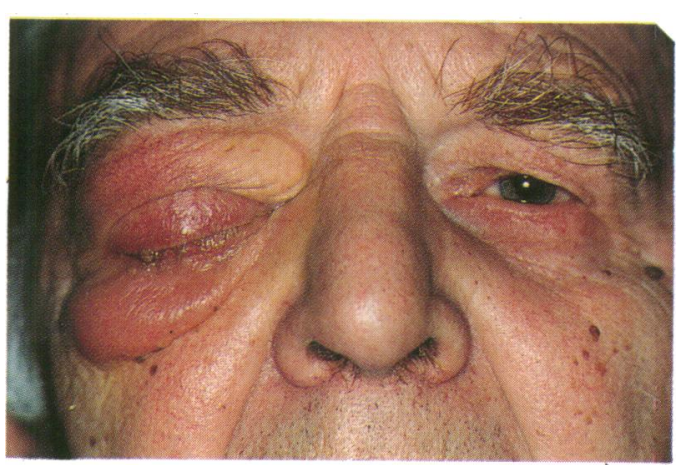

Figure 4 Lesion of the right lid in case 3 on presentation in 1978, also showing ptosis and marked lower lid swelling.

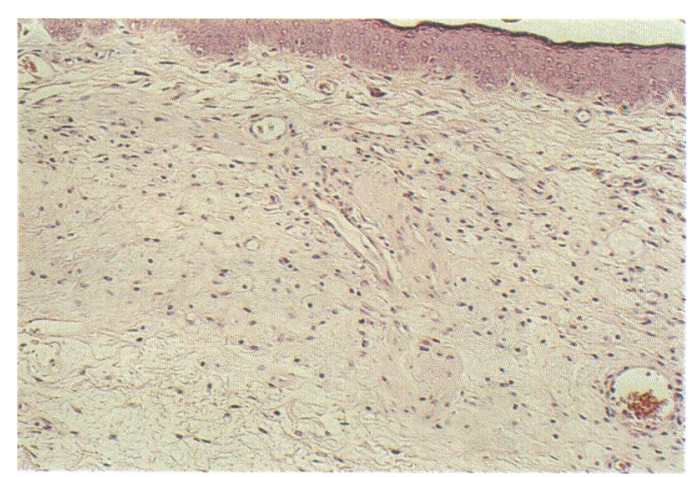

Figure 5 Lid biopsy from case 3 five years after commencement of treatment. There are large numbers of large foamy macrophages within the diffuse xanthelasmatous dermis. Also present are numbers of lymphocytes and macrophages. (Haematoxylin and eosin stain, $\times 75$ magnification.)

Cyclophosphamide was added to oral steroid therapy and the proptosis and disc oedema partially resolved. However, his gaze evoked amaurosis persisted and consequently he underwent right orbital decompression in 1988 with resolution of this symptom. The systemic treatment has been slowly reduced and was stopped in early 1992 . He is currently asymptomatic and the xanthelasmata have practically disappeared. (Fig 3).

ANCA were first tested for in 1990 and were detected at a titre of 1 in 80 . Additional investigations revealed normal renal and liver function, cholesterol $7.0 \mathrm{mmol} / 1$ triglycerides $2.3 \mathrm{mmol} / 1$.

\section{CASE 3}

A 73-year-old man presented in March 1985 with a 5 month history of redness and proptosis of the right eye accompanied by recurrent nose bleeds. Orbital ultrasonography suggested features of an orbital pseudotumour. A therapeutic trial of $40 \mathrm{mg}$ of prednisolone was started which produced some slight improvement. He was referred to the Manchester Royal Eye Hospital where gross right proptosis was noted, the globe being displaced downwards and outwards with complete ophthalmoplegia. There was marked lid swelling on this side and a discrete raised yellowish patch on the superonasal aspect of the right upper lid was noted (Fig 4). No tendon xanthomata were present, nor were other types of xanthomata present elsewhere. Visual acuities were

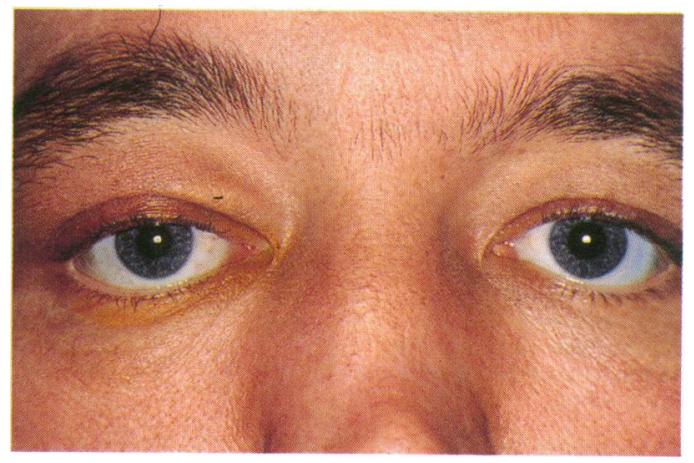

Figure 6 The relatively small raised yellow banana-shaped lesion of the right upper lid in case 4 on presentation in 1987. 
'counting fingers' in the right eye and 6/9 in the left eye with a right afferent pupil defect. Biomicroscopic examination revealed PUK affecting $360^{\circ}$ of the right eye with two necrotic areas of scleritis. The right fundus showed marked retinal venous congestion and cotton wool spots around the optic disc. Computed tomography scan showed a mass situated in the medial aspect of the right orbit which appeared to be surrounding the medial rectus muscle and showed slight enhancement on the post contrast films. There was a mucosal thickening of the right maxillary antrum on plain $x$ ray.

Chest $x$ ray revealed several cavitating lesions in the right middle lobe. Other investigations included erythrocyte sedimentation rate, $65 \mathrm{~mm}$ in 1 hour, haemoglobin $12 \cdot 2 \mathrm{~g} / \mathrm{dl}$, a normal differential white cell and platelet count, but a raised mean cell volume. Urea and electrolytes, C-reactive protein and immunoglobulins, and electrophoresis were all normal.

A diagnosis of WG was made and treatment with cyclophosphamide $50 \mathrm{mg}$ twice daily was added to his oral steroids. All his ocular signs became stable and visual acuity recovered to $6 / 12$ in the right eye. Cyclophosphamide was stopped after 2 years. Eight years after the onset of his condition he remains well on enteric coated prednisolone $10 \mathrm{mg}$ daily. In 1990 he underwent cataract extraction in the left eye for steroid related opacities, at which time a right upper lid biopsy (Fig 5) was taken from a now barely discernible lid lesion. ANCA were absent in February 1990 and again in March 1991. Investigation of his serum lipoproteins in 1991 gave the following results: serum cholesterol was $8.3 \mathrm{mmol} / \mathrm{l}$, low density lipoprotein cholesterol (LDL) $6.3 \mathrm{mmol} / 1(245 \mathrm{mg} / \mathrm{dl})$, high density lipoprotein cholesterol $1.4 \mathrm{mmol} / \mathrm{l}$, and fasting serum triglycerides $1.2 \mathrm{mmol} / \mathrm{l}$. Thus his total serum cholesterol was elevated as a result of an increase in LDL indicating type IIa hyperlipoproteinaemia. His apolipoprotein $\mathrm{E}$ phenotype was $4 / 4$.

\section{CASE 4}

A 33-year-old man was referred to the Manchester Royal Eye Hospital in November 1987 with a 4 year history of recurrent photophobia, supraorbital pain, proptosis, and swelling of the right eye. There was a 9 year history of bloody purulent nasal discharge with anosmia. Treatment with systemic steroids at another hospital 6 months previously had produced an incomplete response. On examination there was lid swelling, chemosis, and proptosis of the right eye. Two palpable masses were present, one at the superonasal aspect of the left upper lid and one at the inferotemporal margin of the right lower lid. A slightly raised, banana-shaped patch was noted in the superonasal aspect of the right upper lid (Fig 6). No tendon xanthelasmata were present, nor were other types of xanthelasmata present elsewhere. Visual acuity was $6 / 6$ in the right eye and $6 / 18$ in the left, this eye being amblyopic.
A computed tomography scan showed extensive soft tissue masses in both orbits. Plain $x$ ray revealed poorly developed antra suggesting longstanding inflammatory changes and the right ethmoidal sinus was opaque. Other investigations included: normal full blood count, erythrocyte sedimentation rate, and chest $x$ ray. A nasal biopsy showed fibrous tissue with chronic inflammatory cell infiltration and an orbital biopsy revealed sclerosing angiitis with marked fibrosis. ANCA were strongly positive with a titre of 1:300, C-reactive protein was $0.03 \mathrm{~g} /$, serum cholesterol was $5.8 \mathrm{mmol} / \mathrm{h}$, LDL cholesterol $3.5 \mathrm{mmol} / \mathrm{HDL}$ cholesterol $1.6 \mathrm{mmol} / \mathrm{l}$, and the fasting serum triglyceride concentration was $1.2 \mathrm{mmol} / 1$. Azathioprine $100 \mathrm{mg}$ daily was added to his pre-existing treatment of prednisolone $25 \mathrm{mg}$ daily and the orbital signs slowly resolved over the ensuing 18 months. The yellowish discoloration of the skin in upper and lower eye lids gradually resolved over the same period. In 1990 he suffered a recurrence of orbital inflammation associated with visual loss due to optic nerve compression. Pulsed intravenous methylprednisolone and cyclosphosphamide brought about an improvement, and he required a maintenance dose of azathioprine $50 \mathrm{mg}$ twice daily and prednisolone $50 \mathrm{mg}$ to control inflammation. He died suddenly in March 1992 as a result of deep vein thrombosis and pulmonary embolism. A postmortem examination was not performed.

\section{Discussion}

Xanthelasmata were the first manifestation of hyperlipidaemia to be described. ${ }^{6}$ It is, however, recognised that they also occur in individuals whose serum lipids are not clearly elevated, and may have a dominant pattern of inheritance even in the absence of hyperlipidaemia. ${ }^{7}$ This argues for local anatomical factors also being important in the genesis of xanthelasmata. Blood flow may also be important in the pathogenesis and is thought to be a factor in unilateral corneal arcus associated with carotid occlusion, where the cholesterol deposition occurs only in the contralateral eye. ${ }^{8}$ In our experience, however, it is exceedingly unusual for a xanthelasma of any size to occur unilaterally.

The lipid deposits in xanthelasmata are present at least initially in foam cells ${ }^{9}$ which probably represent monocyte/macrophages which have entered the subcutaneous tissues from the blood circulation and have engulfed lipoproteins as is believed to occur in atherogenesis. ${ }^{10}$ The lipid laden macrophages lose their ability to migrate out of the tissues which thus become engorged with lipid. This whole process would be expected to increase as the result of heightened vascular permeability and chemotactic factors associated with inflammation. An example of this is the development of Achilles tendon xanthomata in familial hypercholesterolaemia, which are frequently associated with episodes of tendonitis, and where xanthomata progress more rapidly when the tendonitis is recurrent. ${ }^{11}$ Certainly the 
presence of structurally abnormal vessels - for example, in the normally avascular cornea, may also lead to similar lipid deposition. This can be seen in chronic herpes zoster keratitis, even without hyperlipidaemia. ${ }^{12}$ It seems therefore, that factors potentially involved in the pathogenesis of macroscopic lipid containing lesions include hyperlipidaemia, but that a susceptible anatomical site, and abnormal permeability of vessels are also important.

Our patients were all diagnosed as having WG based on clinical grounds with support from $x$ ray and biopsy, and satisfied the criteria $^{13}$ which distinguish WG from other forms of vasculitis. When the test for ANCA became available it proved to be unequivocally positive only in patient 3 . Both patients 1 and 2 had weakly positive or negative tests for ANCA after 12 and 6 years of treatment respectively which is, however, still consistent with the diagnosis of WG. ${ }^{14} 15$

A rare cause of lipid deposition in the lids which should be considered in such cases is necrobiotic xanthogranuloma ${ }^{16-18}$ in which the lesions are indurated and may ulcerate. They may be associated with paraproteinaemia, myeloma, or leukaemia and can present with skin lesions elsewhere. This may also occur in the absence of hyperlipoproteinaemia or even when hypolipoproteinaemia is present. ${ }^{10}$

Another rare diagnosis deserving of inclusion in the differential diagnoses is ErdheimChester disease in which orbital involvement is itself most unusual. ${ }^{19}$ The condition is characterised by a fibrosing xanthogranulomatous process distinct from the histiocytosis group, in which the lungs, pericardium, and long tubular bones are principally targeted. Of the two known cases with ophthalmic involvement both had bilateral proptosis, severe optic nerve compression, and in one case bilateral lower lid xanthelasmata and lid thinning developed. ${ }^{19}$

In all our patients the yellow lid lesions became apparent within 1 year of the onset of orbital involvement though often several years after the onset of other clinical features of WG. Once appropriate treatment was started there was gradual resolution, not only in bulk of the lesions to palpation, but also in their visibility such that all lesions eventually became barely visible. We believe that in our patients the inflammatory process itself was the cause of xanthomatosis in a susceptible anatomical region despite the presence of relatively normal serum lipids in at least two out of four patients. Of the other two the serum cholesterol levels were $7.0 \mathrm{mmol} / \mathrm{l}$. These were thus at approximately the 75th percentile and above the 95th percentile for the British male population of similar age. ${ }^{20}$ The patient with clearly elevated cholesterol level did not have features of familial hypercholesterolaemia such as tendon xanthomata and his apolipoprotein $\mathrm{E}$ phenotype was 4/4 excluding type III hyperlipoproteinaemia, another primary hyperlipidaemia frequently associated with xanthomata. His type IIa hyperlipoproteinanaemia was most likely, therefore, to be polygenic and of the type not usually associated with florid xanthomatosis. It is thus unlikely that any of our series of patients would have developed florid or unilateral xanthelasmata in the absence of WG.

The advent of ANCA assay is a helpful development and orbital biopsy has some value in WG. ${ }^{21}$ Clinical signs in orbital inflammatory disease are of great importance though involvement of the lids is very rare. ${ }^{22} \mathrm{We}$ therefore wish to draw attention to a 'yellow lid' as an additional clinical sign suggestive of WG, and which should fade after appropriate treatment.

1 Robin JB, Schanzlin DJ, Meiser DM, de Luise VP, Clough JD. Ocular involvement in the respiratory vasculitides. Surv Ophthalmol 1981; 30: 127-40.

2 Spalton DJ, Graham EM, Page NGR, Sanders MD. Ocular changes in limited forms of Wegener's granulomatosis. BrfOphthalmol 1981; 65: 553-63.

3 Fauci AS, Haynes BF, Katz P, Wolff SM. Wegener's granulomatosis: prospective clinical and therapeutic granulomatosis: prospective clinical and therapeutic 1983; 98: 76-85.

4 Bullen CL, Liesegang TJ, McDonald TJD, Remee RA. Ocular complications of Wegener's granulomatosis Ophthalmology 1983; 90: 279-90.

5 Duncker G, Gross WL, Nolle B, Asnus R, Koltze H, Spielmann RP. Orbitale Beteiligung bei Wegenersche Granulomatose. Klin Monatsbl Augenheilkd 1992; 201: 309-16.

6 Addison $\mathrm{T}$, Gull $\mathrm{W}$. On a certain affection of the skin. Guys Hosp Rep Ser 11 1851; 7: 265-70.

7 Jensen J. The story of xanthomatosis in England prior to the First World War. Clin Med 1967; 2: 289-395.

8 Smith JL, Susac JO. Unilateral arcus senilis: sign of occlusive disease of the carotid artery. $\mathscr{F A M A} 1973 ; 226$ : 676.

9 Takahashi K, Naito M. Lipid storage disease: Part 1 Ultrastructure of xanthoma cells in various xanthomatous diseases. Acta Pathol fpn 1983; 33: 959-77.

10 Steinberg D, Parthasarathy S, Carew TE, Khoo JC, Witztum JL. Beyond cholesterol. Modifications of low density lipoprotein that increase its atherogenicity. $N$ Engl f Med 1989; 320: 915-24.

11 Durrington PN. Hyperlipidaemia: diagnosis and management. London: Wright, 1989.

12 Marsh RJ. Argon laser treatment of lipid keratopathy. Br f Ophthalmol 1988; 72: 9004.

13 Leavitt RY, Fauci AS, Bloch AD, Michael BA, Hunder GG Arend WP, et al. The American College of Rheumatology 1990 criteria for the classification Wegener's granulomatosis. Arthritis Rheum 1990; 33: 1101-7.

14 Nolle B, Specks U, Ludemann H, Rohrbach MS, De Remeera, Gross WL. Anticytoplasmic autoantibodies: their immunodiagnostic value in Wegener's granulomatosis. Ann Intern Med 1989; 111: 28-40.

15 Soukiasian SH, Foster CS, Niles JL, Raizman MB. Diagnostic value of antineutrophil cytoplasmic antibodies in scleritis associated with Wegener's granulomatosis. Ophthalmology 1992; 99: 125-32.

16 Robertson DM, Winkelmann RK. Ophthalmic features of necrobiotic xanthogranuloma with paraproteinemia. Am f Ophthalmol 1984; 97: 173-93.

17 Rose GE, Patel BC, Garner A, Wright JE. Orbital xanthogranuloma in adults. $\mathrm{Br} \mathcal{F}$ Ophthalmol 1991; 75 680-4.

18 Cornblath WT, Dotan SA, Trobe JD, Headington JT. Varied clinical spectrum of necrobiotic xanthogranuloma. Ophthalmology 1992; 99: 103-7.

19 Alper MG, Zimmerman LE, La Piana FG. Orbital manifestation of Erdheim-Chester disease. Trans $\mathrm{Am}$ Ophthalmol Soc 1983; 81: 64-85.

20 Mann JI, Lewis B, Shepherd J, Winder AF, Fenster S, Rose L, et al. Blood lipid concentrations and other cardiovascular risk factors: distribution, prevalence and detection in Britain. $B M \mathcal{F}$ 1988; 296: 1702-6.

21 Kalina PH, Lie JT, Campbell RJ, Garrity JA. Diagnostic value and limitations of orbital biopsy in
Wegener's granulomatosis. Ophthalmology 1992; 99: 120-4.

22 Jordan DR, Addison DJ. Wegener's granulomatosis. Eyelid and conjunctival manifestations as the presenting feature in two individuals. Ophthalmology 1994; 101: 602-7. 